\title{
A RARE FOREIGN BODY IN THE EAR: REMOVED BY CANALOPLASTY: A CASE REPORT
}

T. Shankar ${ }^{1}$, D. Ranganath Swamy2 ${ }^{2}$ T. Vivechana ${ }^{3}$

\section{HOW TO CITE THIS ARTICLE:}

T. Shankar, D. Ranganath Swamy, T. Vivechana. "A Rare Foreign Body in the Ear: Removed by Canaloplasty: A Case Report". Journal of Evolution of Medical and Dental Sciences 2015; Vol. 4, Issue 67, August 20;

Page: 11762-11768, DOI: $10.14260 /$ jemds/2015/1695

ABSTRACT: Getting an object impact in the ear canal is a relatively common problem in children, the majority of items are lodged in the external auditory canal which is the small channel that ends at the ear drum. The children often place these items in their ears out of curiosity. Common objects found in ear include beads, toys, food material, insects and seeds etc. usually foreign body ear are removed by syringing or with Hartmann's forceps, we are here presenting a case of foreign body in the middle ear removed by canaloplasty through post-aural approach.

KEYWORDS: Foreign body, ear canal, canaloplasty, middle ear cavity, tympanic membrane.

INTRODUCTION: The children often insert foreign bodies in their ears out of curiosity. Foreign bodies in the external auditory canal are more common in children than adults, children often do not tell their parents that they have put foreign body in the ear for fear of being beaten, it is often goes undetected and may be found incidentally. In rural areas of developing countries a dead housefly or maggots is commonly seen in the ears of children having ear discharge due to CSOM.

\section{Anatomy of External Auditory canal/Middle Ear:}

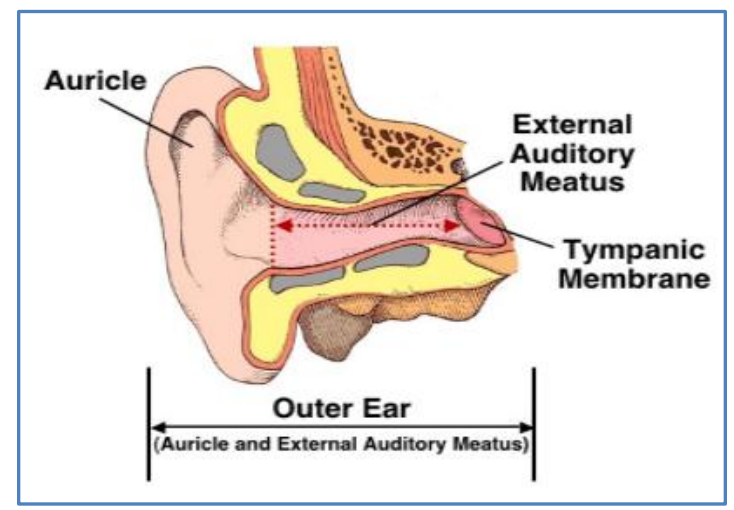

\section{Fig. 1: Anatomy of EAC}

EXTERNAL AUDITORY CANAL: (Figure No. 1): It is $2.5 \mathrm{~cm}$ long in adults and extends from the bottom of the concha to the tympanic membrane. The outer $1 / 3^{\text {rd }}$ is cartilaginous and inner $2 / 3^{\text {rd }}$ is bony part, the tympanic membrane lies obliquely at the medial end of external auditory canal. The external auditory canal is a 'S' shaped tortnous canal and this tortnosity helps to protect the tympanic membrane form injury, medially and anterio inferiorly the bony wall dips down to form a recess called the anterior recess. It is difficult to visualize and even more difficult to remove foreign bodies and debris lodged in anterior recess. 


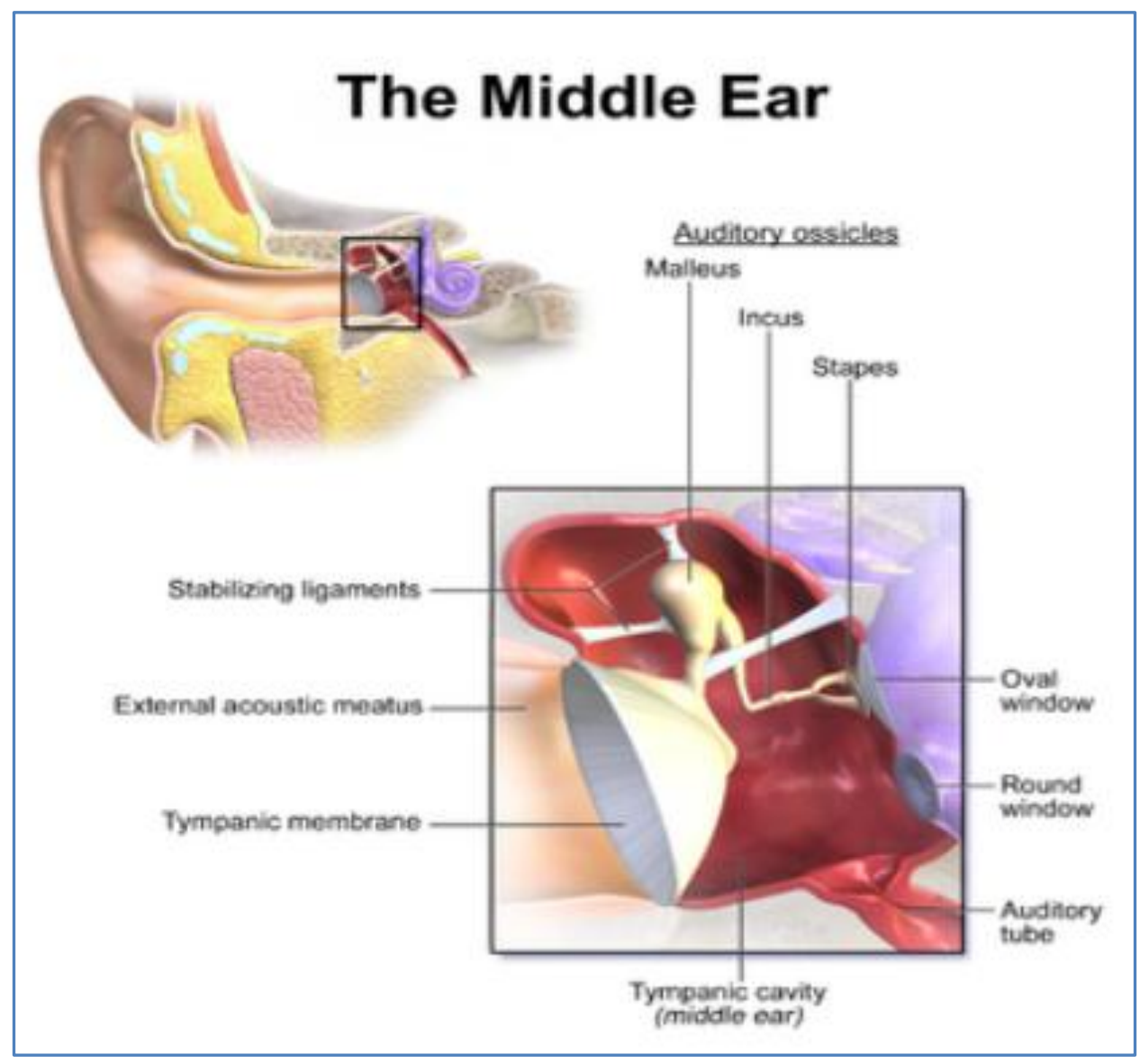

Fig. 2: Anatomy of middle Ear

Middle Ear Cavity: (Figure No. 2): It lies between the external auditory canal and the inner ear and it is shaped like a match box standing vertically.

\section{Parts of the Middle Ear Cavity:}

- Epitympanum (Attic): Part above the malleolar folds.

- Mesotympanum: Part just medial to the pars tensa.

- Hypotympanum: Part that lies below the lower border of tympanic membrane.

\section{Contents of the Middle Ear:}

- Three Ossicles - 1. Stapes 2. Incus 3. Malleus.

- Two Nerves - 1. Chorda Tympani 2. Tympanic plexus.

- Two Muscles - 1. Tensor tympani 2. Stapedius.

\section{Common Foreign Bodies in the External Auditory Canal:}

- Inanimate foreign body: Sponge, eraser, pieces of paper, lead of Pencil, \& cotton wool.

- Vegetable matter: Beans, seeds etc.

- Insects: Housefly, maggots, flea, tick etc. 


\section{CASE REPORT}

Common Symptoms in the Foreign Body Ear: The symptoms of having a foreign body in the ear largely depends on the size, shape and substances involved:

- Pain is the common symptom.

- Decrease in hearing.

- Irritation to the ear canal can also make patient nauseated.

- Bleeding is also common, especially if the object is sharp or if try to remove it by sticking something else in to the ear.

- Occasionally a foreign body in the ear will go undetected and cause an infection in the ear, ongoing infectious drainage from the ear.

- The insect's movement can cause a buzzing in the ear and may be quite uncomfortable.

\section{TREATMENT: Methods of Removal of Foreign Body Ear:}

- Ear Syringing: Ideal for most of the foreign body removal specially when microscope is not available.

- Removal under Microscope: This is safest method of removal of foreign body with help of either suction, Jobson Horne's Probe, blunt ear hook or micro ear forceps.

- Use of Head Mirror and Ear Instruments: With help of ear hook, micro ear forceps or Jobson Horne's Probe.

- Live insects in the external auditory canal should be first killed by putting oil, $2 \%$ xylocaine drops or water in external auditory canal and then only removed, most of the foreign bodies can be removed without anaesthesia, however in uncooperative children or an impacted foreign body, should be removed under general anaesthesia using microscope or otoendoscope to avoid damage to ear drum and pushing the foreign body in to the middle ear cavity, which makes ultimate removal of the object more difficult.

CASE REPORT: A 12 year male child brought to the OPD, Govt. ENT Hospital, Koti, Hyderbad, with chief complaints of insertion of foreign body in the (L) ear, patient was apparently asymptomatic 10 days back, he was developed pain in the (L) ear and taken to private hospital at Nizamabad, there it was diagnosed as foreign body in the ear canal, local doctor was made an attempt to remove the foreign body and failed, finally the case was referred to our hospital for better treatment.

On Examination: External auditory canal was filled with blood clots, no other findings, after necessary investigations the case was posted for endoscopic removal of foreign body under general anaesthesia.

Operative Procedure: Under aseptic condition with help of $0^{0}$ endoscope, external auditory canal was cleaned with normal saline to remove the blood clots, the foreign body (Grayish white beat) seen in the middle ear cavity, foreign body was mobilized with help of a probe and tried to remove, we also failed to remove, since it was very much impacted in hypo tympanum of middle ear, after two to three attempts, we have decided to go post-aurally to remove the foreign body. The post aural incision was given, tympanomeatal flap elevated, foreign body seen tried to remove, it was so much impacted there was no space to negotiate the foreign body. 
Fig. 3: Intra Operative Photos.

A: Elevating the tympanomeatal flap.

B: Canaloplasty.

C: Foreign body in the Middle Ear.

D: Foreign body, after removal.

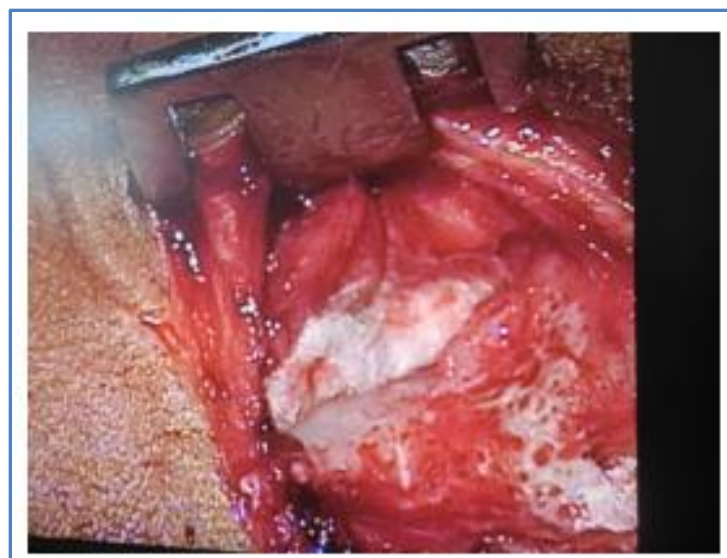

A

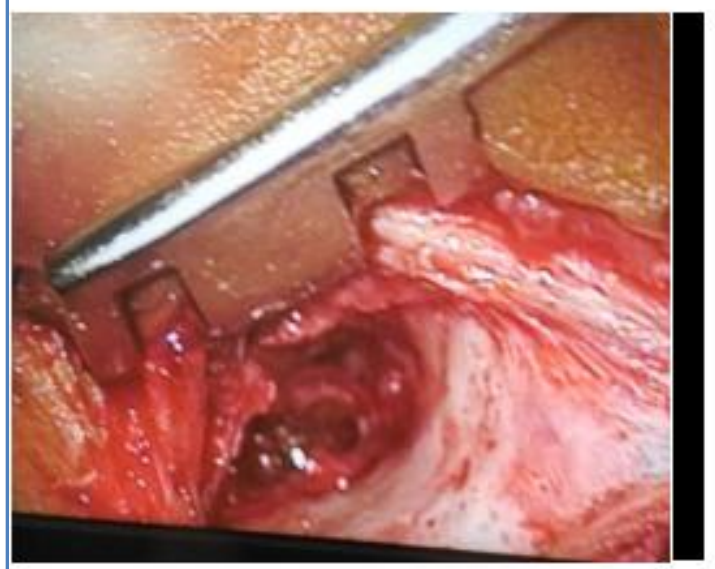

$\mathrm{C}$

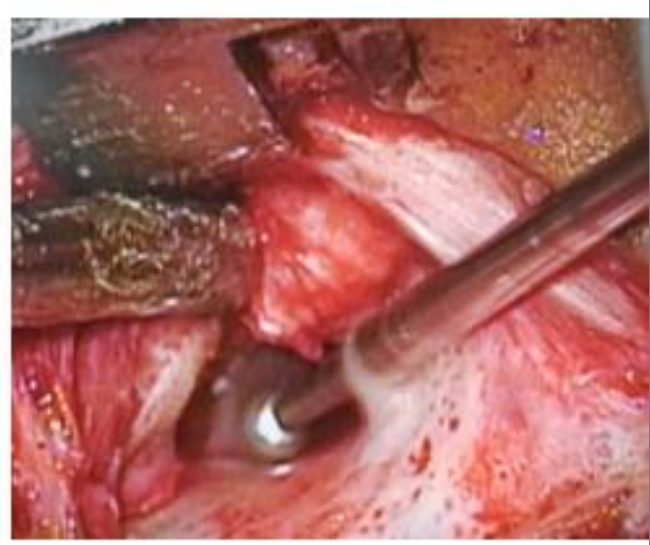

$\mathrm{B}$

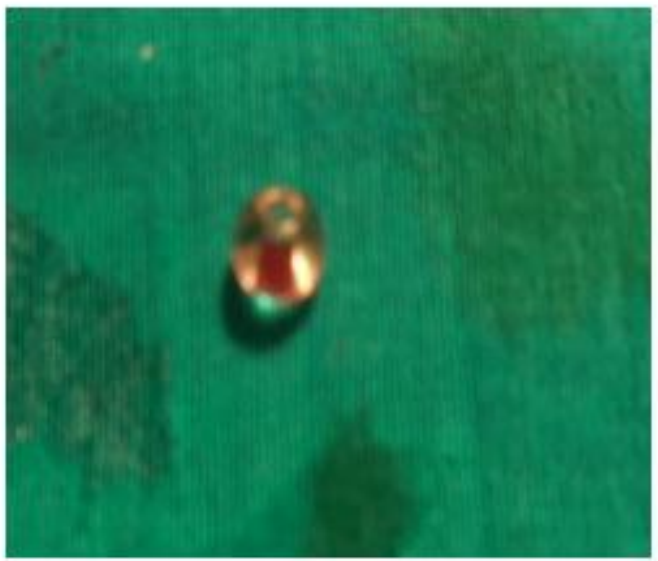

D

Than canaloplasty was planned, slowly under microscope the bony posterior meatal wall was drilled out, till we could remove the foreign body safely. After foreign body removal, again the tympanic membrane and middle ear cavity was examined, entire tympanic membrane was perforated, all the ossicles expect head of the stapes were damaged. The wound was closed in layers, external auditory canal was packed with BIPP pack, was removed on $5^{\text {th }}$ day, sutures removed on $7^{\text {th }}$ day, patient was discharged by advising him for Ossiculoplasty after 8-10weeks.

DISCUSSION: The management of ear canal foreign body in children can be challenging. The external auditory canal narrows at the bony cartilaginous junction, foreign bodies can become impacted at this point (Figure No. 4), increasing the difficulty of removal. Foreign body of the ear are relatively common and are most often seen in children.(1) 


\section{CASE REPORT}

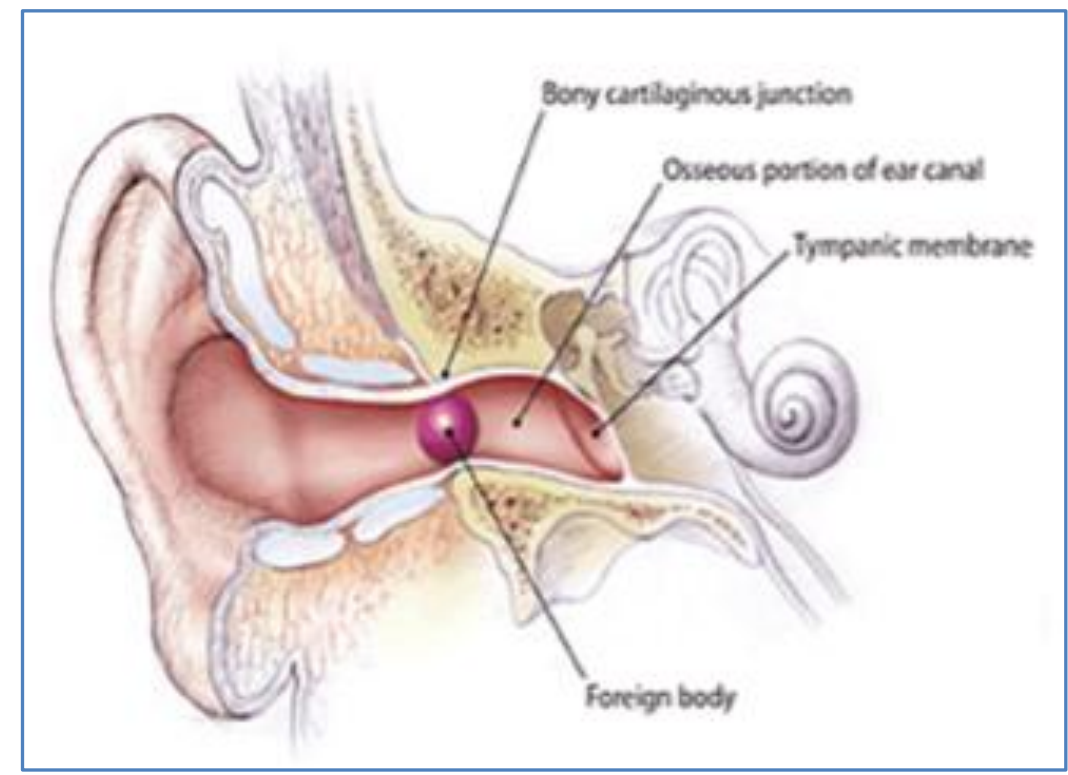

Fig. 4: Common Site for Foreign Body Impaction in EAC

The external auditory canal is a cartilaginous and bony passage lined with a thin layer of periosteum and skin, the osseous portion is extremely sensitive because the skin provides little cushion over the underlying periosteum, thus attempts at foreign body removal can be more painful. Adequate visualization, appropriate equipment, a cooperative patient and a skilled physician are the keys to remove the foreign body successfully.(2) Multiple attempts at ear foreign body removal are associated with increased risk of pain, bleeding, loss of cooperation and serious otologic complications.

\section{Uncommon but Potentially Otologic Complications of Ear Foreign Body Removal Includes:}

- Ossicular chain damage.

- Vertigo

- Tympanic membrane perforation

- Facial Nerve Paralysis.

In many cases, patients with foreign body in the ear are asymptomatic, and in children the foreign body is often an incidental finding, $(3,4)$ other patients may present with pain, hearing loss, symptom of otitis media, or a sense of ear fullness. In several large case series focusing on children, researchers found that $75 \%$ of patients with ear foreign bodies were younger than 08 years.(5) The most common ear foreign body includes beads, plastic toys, eraser, pebbles and popcorn kernels.(5)

Approaches: A variety approaches exist for removing the foreign body in children's ear canal, all of these required optimal visualization of the foreign body, which is best achieved by using the excellent light and magnification afforded by a binocular microscope, the use of endoscopes in ear surgery have increased in recent years. 
Technique: Many techniques to remove ear foreign body are available, and the choice depends on the clinical situation and the type of foreign body suspected, options includes water irrigation (syringing), forceps removal, cerumen loops, right angle ball hooks and suction catheters. The live insects can be killed rapidly by instilling alcohol, $2 \%$ xylocaine or mineral oil in to the ear canal, this should be done before removal is attempted but should not be used when the tympanic membrane is perforated. Irrigation should be avoided in patients with button batteries in the ear because the electrical current and /or battery contents can cause a liquefaction tissue necrosis.(6) Acetone may be used to dissolve Styrofoam foreign bodies(7) or to loosen cyanoacrylate (superglue).(8)

The first attempt at removal is critical because success rate decreases after the first failed attempt, accordingly, complications increase as the number of failed removal attempts increases, $(9,10)$ multiple foreign bodies are not uncommon, especially in small children, one should inspect the external auditory canal after foreign body removal.(11)

\section{The Techniques of Ear Foreign Body Removal Rely on Various Instruments and Aids Including} the:

- Right angle hook.

- Jobson Horne's probe.

- Otologic forceps.

- Cyanoacrylate (Super glue).

- Suction catheters.

Right Angle Hook and Jobson Hornes' Probe: This instrument is particularly helpful for spherical objects, which cannot usually be captured with a wire loop or ear curette.

Otologic Alligator Forceps: This can be used to remove easily graspable objects such as paper, stickers, foam, felt and cotton.

Cyanoacrylate (Super Glue): On the wooden end of a cotton - tipped applicator(12,13): This technique is used in co-operative patients with foreign body that are not easily grasped with other available tools this has the advantage of appealing to some children, who find the wooden end of a cotton swab less intimidating the metallic instruments.

CONCLUSION: The vast majority of items are lodged in the external auditory canal, which is the small channel that ends at the ear drum. The foreign body should be removed by at most care, possibly under microscope. This paper is presented because of complication occurred (Pushing the foreign body in to the middle ear cavity) during removal of foreign body, emphasizing meticulous examination under microscope and removal by not injuring the ear drum and middle ear structures as in this case.

This is the first time in our institution the canaloplasty was done to remove the foreign body ear, which is a rare indication. We should educate and trained the general practitioners and family physicians, how to remove the foreign body ear or when to refer the case to an ENT surgeon for better treatment to avoid complications. 


\section{REFERENCES:}

1. Ong ME, Ooi SB, Manning PG; A review of 2, 517 childhood injuries seen in a Singapore emergency department in 1999-mechanisms and injury prevention suggestions. Singapore Med J. 2003 Jan; 44(1): 12-9.

2. Heim SW, Maughan KL. Foreign bodies in the ear, nose and throat. Am Fam Physician 2007; 76: 1185-1189.

3. DiMuzio J Jr, Deschler DG. Emergency department management of foreign bodies of the external ear canal in children. Otol Neurotol 2002, 23: 473-5.

4. Brown L, Denmark TK, Wittlake WA, vargas EJ, Watson T, Crabb JW. Procedural sedation use in the ED: management of pediatric ear and nose foreign bodies. Am J Emerg Med 2004; 22: 310-4.

5. Ansely JF, Cunningham MJ. Treatment of aural foreign bodies in children. Pediatrics 1998: 101(4 pt 1) 638-41.

6. Mc Rae D, Premachandra DJ, Gatland DJ. Button batteries in the ear, nose and cervical esophagus: a destructive foreign body. J Otolaryngol 1989; 18: 317-9.

7. White SJ, Broner S. The use of acetone to dissolve a Styrofoam impaction of the ear. Ann Emerg Med 1994; 23: 580-2.

8. Abadir WF, Nakhla V, Chong P. Removal of superglue from the external ear using acetone: case report and literature review. J Laryngol Otol 1995; 109: 1219-21.

9. Balbani AP, Sanchez TG, Butugan O, Kii MA, Angelico FV Jr, lkino CM, et al. Ear and nose foreign body removal in children. Int J Pediatr Otorhinolarynol 1998: 46: 37-42.

10. Schulze SL, Kerschner J, Beste D. Pediatric external auditory canal foreign bodies: a review of 698 cases. Otolaryngol Head Neck Surg 2002; 127: 7-8.

11. Thompson SK, wein RO, Dutcher PO. External auditory canal foreign body removal: management practices and outcomes. Layrngoscope 2003; 113: 1912-5.

12. Singh GB, Sidhu TS, Sharma A, et al. Management of aural foreign body: An evaluative study in 738 consecutive cases. Am J Otolaryngol 2007: 28: 87-90.

13. Hanson RM, Stephens M. Cyanoacry-late-assisted foreign body removal from the ear and nose in children. J Paediatr child Health 1994: 30: 77-78.

\section{AUTHORS:}

1. T. Shankar

2. D. Ranganath Swamy

3. T. Vivechana

\section{PARTICULARS OF CONTRIBUTORS:}

1. Professor, Department of ENT, Osmania Medical College, Hyderabad.

2. Assistant Professor, Department of ENT, Osmania Medical College, Hyderabad.

3. Resident, Department of ENT, Osmania Medical College, Hyderabad.

FINANCIAL OR OTHER COMPETING INTERESTS: None

\section{NAME ADDRESS EMAIL ID OF THE} CORRESPONDING AUTHOR:

Dr. T. Shankar.

Flat No. 401, Plot No. 59 \& 62, GK's Rishitha Mari Gold Apartments, Hasthinapuri Colony, Sainikpuri, Hydrabad-500094.

Telangana State.

E-mail: drshankar_ms@yahoo.com

Date of Submission: 03/08/2015.

Date of Peer Review: 04/08/2015.

Date of Acceptance: 17/08/2015.

Date of Publishing: 20/08/2015. 